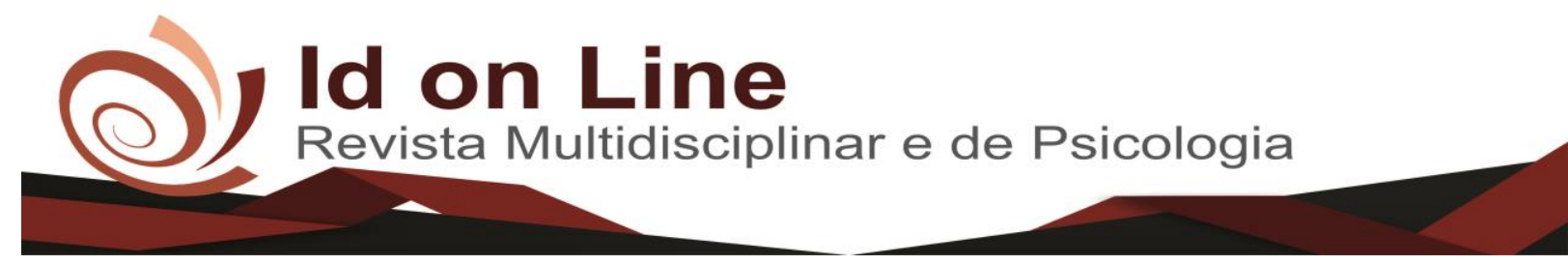

Comment

\title{
A Relevância do Contador para o Microempreendedor Individual (MEI)
}

\author{
Maria Aparecida Silva Morais ${ }^{1}$; Raimundo Ivan Feitosa Filho ${ }^{2}$
}

\begin{abstract}
Resumo: O presente trabalho tem como tema "a relevância do contador para o microempreendedor individual (MEI)", abordando o contador como suporte para o microempreendedor, evidenciando seus direitos e obrigações. Para isto, o contador é fundamental para todas as empresas, seja elas de grandes ou pequenos portes, até mesmo o microempreendedor, não tendo o contador somente com a finalidade fiscal, mas tendo como suporte para gestão empresarial, com um papel fundamental junto com empreendedor. Conclui se neste trabalho que o contador continua sendo indispensável também para essa categoria, em todos os processos da sua empresa no início e nos movimentos auxiliando o empresário qual melhor caminho a seguir, com o intuito de continuar no mercado de trabalho e que possa elevar com segurança.
\end{abstract}

Palavras chave: contador, relevância, microempreendedor individual.

\section{The Relevance of the Accountant for the Individual Microentrepreneur}

\begin{abstract}
This work has as its theme "the relevance of the accountant to the individual microentrepreneur", approaching the accountant as a support for the microentrepreneur, evidencing his rights and obligations. For this, the accountant is fundamental for all companies, be they big or small, even the microentrepreneur, not having the accountant only for the fiscal purpose, but having as support for business management, with a fundamental role together with entrepreneur . It concludes that in this work the accountant is still indispensable for this category, in all the processes of his company at the beginning and in the movements, helping the entrepreneur what better way to go, with the intention of continuing in the labor market and that can raise with safety.
\end{abstract}

Keywords: accountant, relevance, individual microentrepreneur.

\section{Introdução}

É notório que a contabilidade cada vez mais tem tomado uma posição indispensável no dia a dia das empresas. O profissional da contabilidade detém de um papel de suma importância

\footnotetext{
${ }^{1}$ Graduação em andamento em Ciências Contábeis. Faculdade Leão Sampaio, UNILEÃO, Juazeiro do Norte, Ceará, Brasil.moraiskiss@gmail.com

${ }^{2}$ Especialização em Contabilidade Tributária pela Faculdade de Juazeiro do Norte, Brasil. Professor do Centro Universitário Dr. Leão Sampaio, Brasil.
} 
dentro de uma empresa, além dele saber utilizar de todos os recursos que sua profissão dispõe, ele orienta e auxilia o funcionamento, fazendo com que a empresa se organize e traga um diferencial aos demais concorrentes.

Estes profissionais no seu entendimento auxiliam as empresas, estimulando os empresários, a melhorar o seu método de empreender, desenvolvendo habilidades gerenciais, auxiliando também nas tomadas de decisões, através dessas informações, o empresário consegue ter uma noção de como sua empresa está, consegue avaliar sua situação patrimonial, bem como planejar atividades de longo e curto prazo.

O Microempreendedor Individual veio para as pessoas que trabalhe por conta própria possa se legalizar como microempreendedor, conseguindo assim, além de sua regularidade, benefícios e obrigações previdenciários.

Esta Lei Complementar $n^{\circ} 128 / 2008$, que criou a possibilidade dos trabalhadores se regularizarem e terem benefícios, ela dispensa a obrigatoriedade da mesma de manter sua escrituração contábil, consequentemente da contratação de um contador, todavia o contador pode ser cotado como uma assessoria fundamental em certos processos da empresa: pode-se citar: registro de funcionários, licitações, faturamento; nestes processos que o empresário pode contar com as vantagens que a contabilidade oferece.

Diante desta não obrigatoriedade de um profissional da contabilidade, para auxiliar o empresário nos processos contábeis de sua empresa, nasce a seguinte problemática, quais as contribuições, que o contador proporciona ao microempreendedor individual (MEI)?

Este trabalho traz seu corpo, conceitos de empreendedorismo, MEI e contador; as características do empreendedor de sucesso; os tipos de empreendedores; e como os contadores podem auxiliar de forma positiva nas empresas.

\section{Setor Informal}

Segundo Theodoro (2000), o termo setor informal, aparece inicialmente em meados dos anos 70 gerado no seio da Organização Internacional do Trabalho (OIT). O conceito de setor informal surge como uma nova ferramenta explicativa para um velho fenômeno: a existência de atividades econômicas de baixa produtividade que se desenvolvem a margem da legislação.

Para isso, surgiu auto emprego como significado de trabalho informal é a alternativa de sobrevivências adotadas por os trabalhadores, que, por mostrarem dificuldades de ingressar ou 
retornar ao mercado de trabalho, alcançaram renda através de formas de trabalho por conta própria.

Conforme Cleps (2009), o termo informal, pode significar ocorrências muito distintas, como por exemplo: sonegação fiscal, terceirização, comércio de rua ou ambulante, contratação ilegal de trabalhadores assalariados, trabalho temporário, trabalho em domicílio, trabalhador avulso, entre outros.

Em primeiro momento a Lei $\mathrm{n}^{\circ}$ 123/06, garantiu benefícios para as microempresas e/ou Empresas de Pequeno Porte que optassem pelo Simples Nacional. Mesmo com a garantias destes benefícios, os profissionais autônomos e os profissionais ambulantes, ainda detinham de certa dificuldade para obter seu registro, no que se diz respeito a parte burocrática de abertura de empresa, muitas vezes deixando de se regularizar e funcionando de forma informal.

Partindo da problemática que os profissionais ambulantes e os autônomos tinham de se regularizarem, houve a alteração na redação da Lei n 123/06, constituindo a Lei Complementar $\mathrm{n}^{\mathrm{o}}$ 128/08, que entre suas disposições, assegurou melhores oportunidades para que estes profissionais pudessem exercer suas atividades de forma regularizada como.

\section{Microempreendedor Individual (MEI)}

O governo federal estabeleceu através da Lei Complementar $n^{\circ} 128$, de 19 de dezembro de 2008, uma nova proposta de tributação trazida pela figura do Microempreendedor Individual (MEI).

Com o intuito da regularização das atividades de milhões de trabalhadores que ainda continua na informalidade. A lei entrou em vigor em 01/07/2009, e vigora até os dias de hoje.

Para o SEBRAE o MEI é uma forma inovadora e desburocratizante de legalização de pequenos negócios e serviços, e do pagamento em conjunto de impostos e contribuições, resultando numa vital redução de custos e de obrigações acessórias. O MEI, segundo o Portal do Empreendedor - MEI, é o empresário individual que tem as seguintes condições:

a) tenha faturamento limitado a $\mathrm{R} \$ 81.000,00$ por ano; b) Que não participe como sócio, administrador ou titular de outra empresa; c) Contrate no máximo um empregado; d) Exerça uma das atividades econômicas previstas no Anexo XI, da2018, o qual relaciona todas as atividades permitidas ao MEI. (Portal do Empreendedor - MEI, Brasil 2018).

MEI que significa microempreendedor individual traz em suas condições um limite de faturamento por ano, não pode ter participação em outras empresas como sócio ou titular e ter 
no máximo um empregado contratado que receba o salário-mínimo ou o piso da categoria. Ele será enquadrado no Simples Nacional e ficará isento dos tributos federais (Imposto de Renda, PIS, Cofins).

\section{O Poder do MEI no Desenvolvimento Econômico}

Segundo SEBRAE (2017), em meados na década 80 aconteceu a tentativa de implantação do estatuto das Micros e Pequenas Empresas, onde a parte tributável ficaria menos burocrática. Com a criação da Constituição Federal em 1988, houve um grande avanço para as Micros e Pequenas Empresas- MPE's, no que se refere a forma de tratamento diferenciado e de aspectos como registro, acesso ao crédito e tributação reduzida.

Depois de muito tempo, introduziu o Simples Nacional, que passou a ser um sistema tributável que é previsto por lei, tendo como principal objetivo facilitar o recolhimento de contribuições dos micros, pequenas e médias empresas. Em frente a tantas mudanças na Constituição Federal temos a edição da Lei Complementar 128/08. Com a nova redação foi criada uma forma de tributação simplificada, onde os impostos teriam uma taxa determinada pelo governo para diminuir o número de trabalhadores informais e consequentemente alavancar a economia brasileira (SEBRAE, 2017).

Segundo Souza (2017), o microempreendedor individual é uma ferramenta excelente para quem tem vontade de iniciar seu próprio negócio, sem muitas despesas com impostos altíssimos e sem muita burocracia.

Após algumas experiências com a implantação do MEI, é possível adquirir mercadorias com condições mais vantajosas, além de garantir sua cobertura previdenciária: pensão por morte, aposentadoria especial, aposentadoria por invalidez, auxilio reclusão, salário-família e outros. Também, é facultativa ao microempreendedor individual a contratação de um empregado (LAURENTINO, 2012).

Segundo Cacciamali (2000), o MEI veio formalizar de maneira rápida e eficiente muitos cadastros que antes eram paralisados pela grande burocracia que existia e os preços altos dos valores que eram cobrados. De acordo com o Portal do Empreendedor, é possível enfatizar que há uma facilidade na abertura do MEI, tendo em vista que a própria lei permite o acesso a abertura pelo próprio empresário sem ter a necessidade de serviços contábeis. 


\section{Vantagens e Benefícios para se Tornar uma MEI}

Com a criação da MEI, o trabalhador informal passou a adquirir grandes benefícios dos quais não tinham acesso antes da formalização. Fundamentados pelos seus direitos adquiridos por lei, que vem oferecer diversas vantagens, com intuito de transformá-los em microempreendedores individuais (CACCIAMALI, 2000).

Com a contribuição passar a ter direitos por pensão por morte, não podendo ser pago após o óbito, auxílio reclusão, a partir do primeiro pagamento em dia, não podendo pagar após a reclusão

\section{Vantagem para a Empresa}

Para Cacciamali (2000), empreendedor individual pode contratar um funcionário pagando um salário mínimo com a carga tributária reduzida a 3\% de previdência e $8 \%$ de FGTS. O empreendedor não pagará nada ao se formalizar, apenas recolherá uma taxa mensal de INSS, que o valor será conforme a atividade escolhida.

O trabalhador passa a ter inscrição no Cadastro Nacional de Pessoa Jurídica (CNPJ) e com isso consegue emitir nota fiscal, participar de licitações públicas, fazer vendas por meio de máquinas de cartão de crédito. Ele também tem acesso aos benefícios do INSS.

Quem contribui para INSS, a previdência social paga ao se formalizar para o microempresário como para a família tais como, aposentadoria por idade para as mulheres com 60 anos e homem aos 65, observado a carência, que é tempo mínimo de contribuição de 15 anos, por invalidez contribuindo por no mínimo $12 \mathrm{meses}$, contando do primeiro pagamento em dia e 10 meses de contribuição, contando do primeiro pagamento em dia, para salário maternidade

\section{Empreendedorismo}

Conforme Dornelas (2016), o incipiente referencial que a palavra empreendedorismo poderia estar sendo utilizada foi pelo Marco Polo na tentativa de criar uma rota comercial para o Oriente. Também faz uma análise secular mostrando que na idade média o termo foi empregado aos que gerenciava projetos de produção, todavia não assumiam os riscos deixando 
a cargo do Governo. No século XVII começaram a apresentar indícios de relação entre assumir riscos e empreendedorismo, bem como já havia diferença entre capitalista e empreendedor.

A origem da palavra empreendedorismo vem do verbo francês "entrepreneur" que significa aquele que assume riscos e começa algo de novo, o empreendedorismo vem da ação do empreendedor.

Segundo Cielo (2001), o empreendedorismo é constituído de muitos materiais diferentes e com a determinação também diferente em cada empreendedor, contudo, acredita-se que existem características, maneiras de agir e pensar que proporcionam o surgimento de indivíduos dotados de um absoluto “espírito empreendedor”. Raramente, esses indivíduos têm sucesso, em áreas para as quais não se formaram na escola, ou com as quais não estiveram ligados durante a maior parte de suas vidas. Esse diferencial é o denominado potencial empreendedor.

\section{Perfil do Empreendedor}

Conforme Mai (2006) abrange na sua opinião que, se uma pessoa tem características comportamentais e habilidades mais frequentemente encontradas em empreendedores bemsucedidos, terá melhores condições para empreender.

Por outro lado, apesar de não ser somente as características empreendedoras que garantirão o pleno sucesso, sem elas a pessoa poderá encontrar dificuldades em alcançar o sucesso empresarial.

Antes de se iniciar no mundo empresarial é importante que o empreendedor realize um auto avaliação, refletindo honesta e objetivamente sobre os aspectos fundamentais de sua personalidade.

\section{Obrigações}

Sendo fácil e pouco burocrático para o desempenho do negócio, o microempreendedor individual está submisso, a algumas obrigações como a contribuição mensal e declarar anualmente para a Receita Federal quanto faturou.

Segundo SEBRAE, O Documento de Arrecadação do Simples Nacional (DAS): é o instrumento pelo qual o MEI recolhe a sua contribuição mensal. Podendo ser por débito automático, boleto bancário ou pagamento online. Declarações Anuais de Faturamento 
(DASNSIMEI): informar para o Fisco quanto faturou anualmente por meio desse documento, que fica disponível do Portal do Empreendedor.

A demora na entrega da declaração será multada no valor mínimo de $\mathrm{R} \$ 50$. A multa é gerada assim que a declaração é enviada. A contribuição é de $\mathrm{R} \$ 47,70$ por mês, que pode ser acrescida de $\mathrm{R} \$ 1, \mathrm{R} \$ 5$ ou $\mathrm{R} \$ 6$, conforme o ramo de atividade exercida pode ter um funcionário contratado, tendo que cumprir as obrigações trabalhistas. As mais importantes delas são: Recolher mensalmente o INSS, FGTS, apresentar anualmente a Relação Anual de Empregados - RAIS, ao Ministério do Trabalho e Emprego.

\section{Contador}

A contabilidade existe desde os primórdios da colonização e, durante um extenso período, foi tida como a profissão da escrituração mercantil. Utilizava técnicas específicas que foram se aperfeiçoando e especializando, sendo algumas delas aplicadas até hoje.

Conforme Ribeiro Filho, Lopes e Pederneiras (2009, pág. 22), já existiam registros de fundamentos contábeis há cerca de 4.000 a.C., verificados na história da antiga Suméria, da Mesopotâmia e do Antigo Reino Egípcio, como controle de bens, verificados nos objetos encontrados de escavações realizadas nas regiões do Oriente.

Segundo Marion (2003, p. 25) "a função básica do contador é produzir informações úteis aos usuários da contabilidade para a tomada de decisão”. As empresas modernas precisam cada vez mais de profissionais contábeis que forneçam informações úteis relevantes e oportunas para a tomada de decisão

\section{O contador e sua Relevância com o Desenvolvimento do MEI}

Para Marion (2009, p28) vem falar sobre o cenário social em que vivemos, onde fica cada vez mais visível a importância de profissionais que atuam conforme várias necessidades. Em particular o profissional da área contábil tem a oportunidade de atender a sociedade com informações financeiras, econômicas e sociais, garantindo a veracidade das informações trocadas e atuando diretamente na construção do patrimônio social e financeiro das pessoas.

Para Marion (2009, p. 29) passa a exercer um papel de suma importância em meio ao corporativismo, fornecendo informações que influenciam diretamente na tomada de decisões. 
Precisam estar atentos às constantes mudanças e necessidades do mercado, mantendo-se com importância em sua função.

A contratação de um contador se faz necessária para a execução de procedimentos fiscais e previdenciários quando da contratação de um funcionário, bem como regularização de pendências acerca da atividade empresarial. Conforme determinação legal da lei que regulamenta o MEI, as obrigações acessórias pertinentes às rotinas de admissão, férias, folha de pagamento, cálculo do $13^{\circ}$ salário e rescisão trabalhista, notoriamente demandam conhecimentos técnicos concedidos ao profissional contábil (SPINOLA 2010).

Desta forma, ressalta a importante da contribuição do profissional contábil para as empresas, especialmente para as pequenas, onde as decisões são tomadas dentro da organização com o objetivo de evitar riscos em posicionamentos errados que podem comprometer a continuidade da empresa ou incorrer em prejuízos.

Ainda que seja evidenciada a importância para a tomada de decisão, os MEI's recorrem ao contador mais para tributação fiscal, onde os conhecimentos do profissional contábil são mais utilizados.

\section{Metodologia}

Para Raupp e Beuren (2006), há três tipologias de pesquisas aplicáveis a contabilidade são elas: pesquisas quanto aos tipos de objetivos, aos procedimentos e a abordagem do problema.

Quanto ao objetivo foi utilizada a pesquisa descritiva, conforme Gil (2002) o propósito desta pesquisa é a descrição das características de uma determinada população, bem como a relação entre essas variáveis.

Quanto ao procedimento para realização desta pesquisa foi feita uma pesquisa bibliográfica. Segundo Gil (2002) a pesquisa é baseada por materiais já elaborados como artigos científicos e livros sobre o tema que será pesquisado. Esse procedimento foi feito para reunir conhecimento acerca do tema desta pesquisa, posteriormente feito um levantamento pelo método survey, juntamente aos microempreendedores no DF.

Quanto à abordagem do problema está pesquisa tem caráter qualitativo, dado que busca descrever a realidade da importância do contador para MEI"S. 


\section{Considerações Finais}

O Brasil vem passando por mudanças significativas, entre elas a criação do MEI. A variada gama de atividades que podem ser exercidas pelo MEI, incentiva o desenvolvimento socioeconômico das entidades que atuam na informalidade, dá ênfase ao crescimento da economia e ao desenvolvimento do comércio, por meio de incentivo aos pequenos negócios, os quais tem gerado uma substantiva evolução positiva dos micros empreendimentos.

A contabilidade se utiliza de diversas técnicas e instrumentos, tais como: escrituração, demonstrações contábeis, análise e interpretação das demonstrações contábeis, auditoria e perícia, e por mais que a legislação dispense o Microempreendedor Individual de manter a sua escrituração contábil, por ser simplificado, o contador tem um papel de extrema importância para o sucesso da sua empresa, no momento que o MEI precisa registrar um funcionário, participar de uma licitação ou mudar de porte por excesso de faturamento que o contador é a assessoria ideal para o empresário. Este artigo vem mostrar a relevância do contador para os micros empreendedores, como auxílio na tomada de decisão.

\section{Referências}

BRASIL. (s.d.). Acesso em 19 de 11 de 2018, disponível em SEBRAE: http://www.sebraepr.com.br/PortalSebrae/sebraeaz/Microempreendedor-Individual

BRASIL. (s.d.). Acesso em 19 de 11 de 2018, disponível em SEBRAE: http://www.sebraepr.com.br/PortalSebrae/sebraeaz/MEI-\%E2\%80\%93-Como-preencheraDeclara\%C3\%A7\%C3\%A3o-Anual-Simplificada-(DASN)

CACCIAMALI, Maria Cristina. Globalização e processo de informalidade. Revista Economia e Sociedade, V9, jun. 2000.

CLEPS, Geisa Daise Gumiero. Comércio informal e a produção do espaço urbano em uberlândia (MG). Sociedade \& Natureza, Uberlândia, V. 21, n. 3, dez. 2009. Disponível em: Acesso em 19 de novembro de 2018.

DORNELAS, J. Empreendedorismo Transformando ideias em negócios. 6.ed. São Paulo: Empreende/Atlas, 2016.

FILHO, José Francisco Ribeiro; Lopes, Jorge; Pederneiras, Marcleide. Estudando Teoria da Contabilidade - São Paulo: Atlas, 2009 
MAI, Antonio Fernando. O Perfil do empreendedor versus a mortalidade das micro e pequenas empresas comerciais do município de Aracruz/ES. Dissertação (Mestrado). Vitória: FUCAPE, 2006.

MARION, José Carlos. Contabilidade empresarial 15 ed. São Paulo: Atlas 2009.

Contabilidade empresarial.10.ed.São Paulo:Atlas,2003.

Portal do Microempreendedor Individual. Disponível em: <http://www.portaldoempreendedor.gov.br/mei-microempreendedor-individual >. Acesso em 20 Nov.2018.

RAUPP, F. M.; BEUREN, I. M. Caracterização da Pesquisa em Contabilidade. In: BEUREN, I. M. (Org.). Como elaborar trabalhos monográficos em contabilidade: teoria e prática. 3 eds. São Paulo: Atlas, 2006.

SEBRAE. Serviço Brasileiro de às Micro e pequenas empresas. Disponível em: <www.sebrae.com.br>. Acesso em:21Nov.2018.

SEBRAE. Perfil do Microempreendedor Individual 2012. Série estudos e pesquisas. 2012b. Disponível em: <http://bis.sebrae.com.br/GestorRepositorio/ARQUIVOS_CHRONUS/bds/bds.nsf/a71517 51f28145b2dfddcb8833d4f/\$File/4304.pdf>. Acesso em 22 Nov.2018.

SOUZA, Dayanne Marlene de. Os principais benefícios proporcionados ao trabalhador informal para formalização através do microempreendedor individual. Disponível em: <https://repositorio.ufsc.br/xmlui/handle/123456789/127035. Acesso em 23 Nov. 2018.

SPINOLA, André, Como fica a contabilidade do Empreendedor Individual (EI/?MEI) In:: Direito \& Gestão. Disponível em: <http//andrespinola.com/2010/08/como-fica-contabilidadedo.html/>. Acesso em 19 Nov.2018.

SROUR, R. H. (1994). Poder, cultura e ética nas organizações. Rio de Janeiro: Editora Campus.

THEODORO, Mário. As Bases da Política de Apoio ao Setor Informal. Texto para discussão $\mathrm{n}^{\circ}$. 762. IPEA - Instituto de Pesquisa Econômica Aplicada. Brasília, 2000. Disponível em: $<$ http://scholar.google.com.br/scholarq=As+Bases+da+Pol\%C3\%ADtica+de+Apoio+ao+Seto r+Informal+no+Brasil\&hl=pt-BR\&btnG=pesquisar\&Ir=>. Acesso em 20Nov. 2018.

Como citar este artigo (Formato ABNT):

MORAIS, Maria Aparecida Silva; FEITOSA FILHO, Raimundo Ivan. A Relevância do Contador para o Microempreendedor Individual (MEI).. Id on Line Rev.Mult. Psic., 2019, vol.13, n.43, p. 480-489. ISSN: 1981-1179. 